\title{
A Reflection on Harnessing Learned Optimism, Resilience and Team Growth Behaviour in Order to Support Student Groups
}

\author{
Melinda Chadwick \\ Macquarie University, Sydney, Australia
}

\begin{abstract}
$^{1}$
Change is all around us at universities, and learned optimism is a skill that is much sought after. Our rapid rate of change at Macquarie University has identified the opportunity for the Student Engagement team to implement learned optimism in their training and work practices in order to enhance the student experience. This article will explain the current challenges and how our response to change can set the standard for future challenges. With learned optimism we are able to facilitate positive changes to practices that support the needs of student groups.
\end{abstract}

Keywords: Student engagement; resilience; student experience; learned optimism.

\section{Introduction}

The environment at Macquarie University is rapidly changing. With changes to the campus occurring in order to support future growth, it has become imperative that students and staff are able to engage with the campus and creatively cohabit the spaces provided.

In 2017, Macquarie University opened a new social space for student groups, called MAZE. With breakout areas and customisable furniture, the brief was to make the area work for student group activities. It was apparent that this space created challenges to some student groups, and administrative changes faced by staff meant that users were viewing the space in different ways. With a lot of the University undergoing construction, space was scarce, and it was necessary for staff and students to work collaboratively in order to make the most of MAZE.

Arising from this challenge was the requirement for the University's Student Engagement team to think differently. It was clear to staff that the limitations of the area were fixed, however the way that we worked with student groups was not. With most of our staff also being students at Macquarie University, a unique opportunity presented itself where we were able to provide our student leaders with opportunities to learn and develop resilience and positive mindsets in their work. The goal was for these staff members to become familiar with the theory behind learned optimism and resilience within their working practices and disseminate this information to their student peers and cohorts. With this goal in mind, the team decided to adopt a learned

\footnotetext{
${ }^{1}$ This article was originally presented as an Emerging Initiative at the 2019 STARS Conference and the authors were invited by the Editorial team to submit this to the special issue. It has undergone revisions to align it to the quality expectations of this special issue.
}

This work is licensed under a Creative Commons Attribution 4.0 International Licence. As an open access journal, articles are free to use with proper attribution. ISSN: 2205-0795 
optimism approach to our activities, and to focus on growth mindsets and resilience building strategies for our team that would filter to student group activities.

This article discusses the concepts of resilience, and learned optimism, and their application to the challenges faced by the Student Engagement team and student groups. The article discusses the approaches that Student Engagement implemented to facilitate learned optimism within the team through workshops activities, training and projects. The article also discusses how by creating opportunities for building resilience, the Student Engagement team was able to provide increased support and problem-solving activities for students.

As a specific example of resilience and learned optimism, the article will focus specifically on how we have worked towards adapting to change through some illustrative examples of this process in the Student Engagement team.

One of the strongest opportunities we have to make a difference in the environment is through the way in which we think. Modern psychological discourse has moved away from humans being considered products of their environment (Seligman, 1991). Learned optimism creates stronger teams who produce better quality work. Positive institutions should support the virtues of learned optimism, which in turn supports the creation of positive emotions (Duckworth, Steen \& Seligman, 2005; Seligman, 2004).

It is important also to note that the application of learned optimism in the tertiary administration sector is still emerging. A realistic approach to optimism in practice is required in order to ensure that the foundations of learned optimism and resilience support students to be successful in real terms rather than setting expectations that are difficult to meet.

\section{Resilience in Higher Education}

Resilience can be explained as the capacity to consider outcomes as good, despite threats to adaptation and development (Masten, 2001). It is the process of successful adaptation despite challenging or threatening circumstances (Howard \& Johnson, 2000). When applying the theory of resilience to the higher education sector the context is defined as "the heightened likelihood of success in school and other life accomplishments despite environmental adversities brought about by early traits, conditions, and experiences" (Wang, Haertal \& Walberg, 1994, p. 46).

Resilience in the context of higher education is considered a process of "navigating" oneself toward, and then using resources rather than being considered as a personality trait, given the influence of internal and external systems in the process of building resilience (Rutter, 2007; Ungar, 2008). Influencing factors on resilience include the environment in which we work, socialise and inhabit, as well as a personal interpretation of adversity and challenge (Olson \& Dweck, 2008). Whilst it is acknowledged that resilience is not able to definitively change the outcomes of all students to positive experiences, there is research that indicates that students who have applied resilience to their studies can turn around poor academic performance (Jimerson, Egeland \& Teo, 1999).

Within Student Engagement we have used resilience as a methodology for building the skills and capacity to influence behavioural response to challenges. The aim is to provide students and staff with the capacity to think broadly about change and challenges and look for positive influences and factors when requiring adapting to change. More generally, the ability to adapt and develop resilience is a skill that serves students well as they seek employment. Of interest to Student Engagement is also the study of optimism.

\section{Learned Optimism in Higher Education}

Contemporary approaches treat optimism as a cognitive characteristic, a goal or a casual attribution. Optimism is multidimensional with a determination to accomplish personal goals (agency) and the tendency to plan methods of achieving goals (pathway) (Tariq \& Zubair, 2015). Learned optimism is a response to the proverb "is the glass half empty or half full?" and provides a solution by altering the way we perceive events by conditioning our minds. It is the idea that we can learn to be optimistic and cultivate our own happiness (El Sayed \& Humble, 2018). Students who exhibit self-regulating behaviour such as resilience, a positive mindset and learned optimism are frequently identified as self-starters with persistence and prevail more often over problems that arise (Zito, Adkins, Gavins, Harris, \& Graham 2007). 
Leaders in the field of learned optimism research discovered that people's tendency to give up efforts to change bad outcomes was due to a predisposition to view bad outcomes as being caused by internal, stable and global characteristics (Buchanan \& Seligman, 1995). Learned hopelessness is linked to heightened risk of depression, poor academic performance and stress induced illness when bad events occur (Metalsky, Abramson, Seligman, Semmel \& Peterson, 1982; Peterson \& Barret, 1987; Peterson \& Seligman, 1984; Peterson, Seligman \& Vaillant, 1988). With two personality traits linked to achievement, ability and motivation, the construct has modified slightly to include mindset (optimistic or pessimistic) as an indication of success. The ability to succeed and the desire to succeed are not always enough without the belief that one will succeed, and this is where learned optimism is critical to student success in higher education (Schulman, 1999).

Learned optimism is the process of perceiving events as local, temporary and changeable (El Sayed \& Humble, 2018). Optimism can be learned and developed through cognitive techniques (Hoy, Tarter \& Hoy, 2006). Learned optimism allows people to move away from learned pessimism and can be built through organisations to support individuals and businesses alike (Seligman, 1998). Learned optimism in a higher education context views student as willing, tasks as achievable and allows higher education providers to shift the focus away from pessimism and onto goal-oriented planning and thinking that supports the success of students (Hoy et al., 2006). Learned optimism is a force of motivation for achieving goals even when met with challenges and encourages students and staff to persist until they are successful.

\section{Learned Optimism in Administrative Departments}

Learned optimism is not without its criticisms, with arguments made that "Pollyanna" views of optimistic thought can oversimplify the issues that people face when met with challenges (Peterson, 2000). Researchers have argued that the benefits of optimistic biases can lack logical force (Colvin \& Block, 1994). With inherent emotional and motivational components, optimism can be hard to quantify definitively (Carver \& Scheier, 1990). Achieving a balance between optimism and realism allows an individual to view themselves as slightly better than they are, and that does not typically lead to behaviours that are based on false assumptions (Baumeister, 1988). Therefore it is the aim of Student Engagement to facilitate opportunities for students to expand optimistic thinking in an environment that is supportive and also realistic in terms of success and the goals that can be achieved.

The aim of the Student Engagement team was to provide students with the environment and opportunity to practice learned optimism in the context of their student group activities. Through goal orientated activities and training opportunities, the aim was to provide individuals with small practical achievements where they were able to positively attain goals with greater satisfaction, more competency, and achieve these goals independent of association of groups or peers. The ability to experience learned optimism in this setting would begin to provide students with achievement opportunities that would be positively linked with wellbeing (Halama \& Dedova, 2007).

The Student Engagement team works closely with 150 social and sports groups on campus. With the University experiencing rapid change through environmental and academic environments, it is imperative that the administrative element of the University works with students to support their learning and experience on campus through this change. New buildings and social spaces on campus created new challenges for students and staff in terms of structuring social events, maintaining respect for other users of the spaces, and ensuring that the student groups had the necessary amenities required to run events such as quidditch to networking with business leaders on a regular basis.

Through feedback mechanisms at the University, the Student Engagement team identified the need to provide skills based training that would provide student groups with the opportunity to understand the challenges on campus and identify skills that would assist them with overcoming new challenges in relation to their student group events. Most commonly, the main areas of pessimism were associated with funding, finding new spaces to practice and hold events in, and interpersonal conflict within the groups themselves. In order to address these challenges, the Student Engagement team undertook to provide a range of opportunities associated with training and workshops that allowed students to participate in creating change and experiencing optimism and its efficacy in a tertiary setting.

Through focusing on challenges where the Student Engagement team was able to work in enabling student success in achieving changes in their events it was hypothesised that students would be able to incrementally achieve an awareness of optimistic practices and would apply these to other areas in their education and more broadly in their pursuit for work post-university. 
With research indicating that learned optimism in a work setting increases self-reported levels of engagement, we identified that student group experiences within workshops and training would provide them with opportunities to identify skills that would be valuable for their careers as well as at university (Tariq \& Zubair, 2015).

\section{Student Engagement Initiatives}

With the creation of the new student space at Macquarie University, the Student Engagement team moved to a new open plan office in an area that was shared with student groups. Moving from an enclosed, traditional office into a new shared space created several challenges, for example, relating to privacy, noise, and service hours.

From a student perspective, the new space was customisable and suited to small group meetings and events, but some of the larger groups on campus found it difficult to find sufficient space for their activities, and more active groups like the Dance Academy, and Acapella groups were limited in the areas in which they could practice and perform.

Alongside these physical spaces, the Student Engagement team had employed new staff and organisational changes meant that administrative tasks associated with banking, room bookings and event planning had changed and as the transition occurred there were some delays in processing student group enquiries. As these challenges arose, it was evident that everyone was experiencing rapid change and feedback to staff was that students were unsure how best to use the space. It was through these experiences that the Student Engagement team identified the need for learned optimism to support student activities and establish an increase in trust between the team and student groups. The intended impact of these initiatives was to increase student resilience and optimistic skillsets which would ready them for roles in the future and create employability factors that would be attractive to potential employers.

In order to achieve this goal, the Student Engagement team co created activities with students that were designed to facilitate open communication with student groups. Through rapid feedback, the team was able to understand succinctly if these initiatives were providing students with increased levels of satisfaction and problem-solving skills and redefining the workshops and processes to better support the goals of the training and workshops. The team implemented feedback mechanisms such as surveys, face to face meetings and a consistent open-door policy to communicate concerns about the space and the events being held.

In order to ensure that the team was able to positively impact on optimism and resilience it was imperative that the team was informed about optimistic processes and how best to facilitate them when interacting with students. The team undertook workshops and training that provided practical application of learned optimism such as identifying "three good things" and "savouring" positive experiences so that the team was better able to facilitate these skills and theories in workshops with students (Peterson, 2006; Seligman, Steen, Park \& Peterson, 2005). Whilst these are standalone positive psychological interventions, there has been some evidence that using them collaboratively assists with identifying and understanding instances of positive emotion and its impacts on our interactions with challenges (MacIntyre \& Gregersen, 2013).

Rather than creating optimism that is impractical and frustrating in its futility, the team focused on activities that would encouraged the team to shift the focus away from permanent, pervasive and personal explanations for difficulties toward more temporary, specific and hopeful explanations (Gregersen, MacIntyre, Finegan, Talbot \& Claman, 2014; Seligman, 2004). One of these initiatives was the twice weekly huddles that were held with staff. The aim of these huddles was to create a flat organisational structure, where all staff were empowered to discuss their experiences, concerns, or ideas to improve the current environment. Within these huddles subject matter experts were invited so that the team could upskill and expand the team's knowledge of other areas of the University. The team frequently provided examples of three good things or positive experiences they have had so that we fostered the sense of optimism and could use these 'wins' as momentum for the goals we wanted to achieve with student groups. The huddles were a quick 10-15 minute catch up where any staff member could run and lead, driving the conversation and providing key thoughts and experiences that they thought would be applicable to the other members of the team.

One of the main ideas that came from the huddles was that we required additional information from the students about the challenges they were facing and what they needed the most assistance with. Within the student social space, we were able to use large whiteboards to ask students "what needs to be changed." Through a rapid feedback model, students let us know what 
was on their mind by writing quick notes about the ideas that they wanted to have actioned and what they would need to achieve these goals. The team used these notes to separate the ideas into changes that were critical, which ideas were out of scope and what ideas would be easy to implement and assist in building momentum with the ability to acquire optimistic practices. Through a very visual model of feedback, the team was able to tick off ideas that were implemented (for example, calendars of events that were posted around the space) and provide information to students about the progress of others (such as ideas that required support from other business areas, or were in progress elsewhere).

The team worked together to categorise changes and reported back to the students about the changes that were made, and consistently sought feedback from students to further tweak the ideas.

An example of one of the rapid feedback processes that the team worked on was the creation of online training modules for student group executive training. Students identified the areas of training that were most important for them, and how they wanted this training to be delivered. The Student Engagement team then worked on providing these training modules in an interactive, accessible way that suited the needs of the students. With constant feedback and amendments to the training modules, the Student Engagement team built up a number of different modules for training ranging from event management, social media awareness and financial management that continue to grow as students bring forth their ideas for training.

\section{Measures}

We have also implemented a culture of feedback through open discussion but more typically, through online surveys. The survey system allows the team to receive honest feedback about the processes in place. It also allows students to quickly provide information to the team with the ability to remain anonymous if needed and without impinging on the time-poor lives of many of our students. The online survey process is attractive to students for these reasons and has been a successful way of achieving feedback that is honest in a small amount of time.

The Student Engagement team implemented the training and workshop changes in the second half of 2018 and sought feedback during and after Orientation Semesterv 22018 and Semester 12019 to understand how the team was progressing with providing positive opportunities for students and addressing their concerns in a timely manner. The purpose of the survey was to determine the success of the processes that had been implemented. Considering the large number of surveys that students can be asked to complete during their studies at university, we wanted this process to be quick and easy for them, and so kept the number of questions to a small number. The total number of questions was 27. Demographic information was not collated beyond the type of student group that the participants were representing in the survey.

Questions in the feedback model covered the range of experience from student groups (e.g "is this your first year at Orientation?", "have you been to a training session run by Campus Engagement previously?"). To gather feedback from student groups, we invited students to complete an online anonymous feedback survey that was sent to their email address. We also posted flyers around the University with a QR code to draw interest in the survey. One of the more popular methods of gaining responses to this survey was via direct campaigning, where if a student visited Campus Engagement for another reason, we would encourage them to complete the survey whilst we attended to their other needs. We used iPads for this purpose so that the student could quickly complete the survey.

\section{Results}

The benefits of a rapid feedback model is that the process of implementing and receiving feedback is not onerous on the tasks that the team needs to complete on a day to day basis. One such feedback process was undertaken to receive information about student group participation in Orientation week in Session 2, 2018. From this survey, 25 student groups responded. We were pleased to hear that all of the groups believed that their participation in orientation was successful for their group goals. Of interest to the team was feedback surrounding communication of the week's activities and training associated with orientation. However, $25 \%$ of student groups were not satisfied with the communication channels used.

With this information we were able to conduct further workshops with student groups to understand what elements of the communication process were unsatisfactory and encourage openness to new ideas and methodologies in relation to the communication needs of the student groups. By focusing on the 'good things' from the feedback and where we could make the 
most impactful changes quickly, the team brainstormed through huddles and created new training materials and communication methods for students. This involved utilising online workshop videos, access to additional resources online for training and development, and communicating to students through frequent newsletters and in person training sessions held on different dates and times that were more suited to the student schedule.

Comparing the results from Semester 22018 to Semester 1 2019, we were able to see an increase in the satisfaction of the communication channels used by the Student Engagement team. The satisfaction rate for communication increased from $75 \%$ satisfaction to $80 \%$ satisfaction. We also introduced a Net Promoter Score survey to the students for the first time and received an $80 \%$ promoter score for recommending training and workshops run by Student Engagement, as well as $80 \%$ for recommending students communicate with Student Engagement for events and initiatives.

Additionally, to measure the success of our initiatives we frequently celebrate our achievements through the positive feedback we receive from our student groups. Some of the positive feedback we have received is listed below:

Keep doing what you are doing. The Sustainability Squad is very grateful for all the energy and support Campus Engagement could provide us, without them we would not have had the impact or the reach we were able to in 2018.

The Campus Engagement team has played a significant role in the success of the Women's Collective from the very beginning.

Campus Engagement has helped us tremendously, with all our events. They have been very approachable and welcoming when the Tamil Society was in need.

Just as with last year, our experience with Campus Engagement has been amazing, perhaps even better than last year. Thank you from the Muslim Students Association."

Thank you very much for the $\mathrm{O}$ week stall. We had huge success with it and generated a large amount of interest. Campus Engagement staff did a fantastic job of making sure everything was catered for and that it ran well.

The feedback from student groups was important in focusing the teams attention on the success from the changes implemented, but also an opportunity to reflect on areas that were not otherwise considered as important. Oftentimes it can be difficult in the day to day to know if initiatives are hitting the mark with the student population, so to hear that changes to the processes for orientation were considered helpful and assisted the students with one of their biggest events of the year was encouraging. With positive feedback from the student groups, Campus Engagement was able to continue on the path of implementing change to foster positive outcomes from small initiatives.

\section{Conclusion}

With the combination of staff empowerment and learned optimism, alongside the practical design thinking processes identified in the rapid feedback process, the Campus Engagement team has made significant progress in creating an open communication pathway with students. The experience of a student having their feedback considered and acted upon is significant in terms of providing an opportunity for growth. More importantly, it has real life applicability and provides students with experience that will translate to experiences they can communicate to potential employers in the future. The more we involve students in solutions, the more experience they gain in negotiation, communication and innovation, all of which will be practical in their search for employment when they leave university.

The results from the feedback surveys have indicated that the team is beginning to implement positive changes in work processes that have previously been identified as stressful or difficult for students. With a team centric approach to implementing learned optimism in our work practices, Student Engagement has provided staff with opportunities to consider the problems faced by student groups as temporary and not insurmountable.

Learned optimism is not distinctly new in organisational behaviour and team dynamics, however the application of skills-based learning and building within the team and modelling learned optimism is new for the team. Arguments against learned optimism often centre around the applicability of optimistic thought against pervasive, serious issues in both work and in life. It is important to identify that learned optimism in the higher education context is not applied to retract from the seriousness of concerns or challenges. It is through the use of linguistic terms such as 'challenge' versus 'problem' that makes small 
incremental changes to the way that learned optimism is able to be applied to the work that Student Engagement completes. For example, the term problem is synonymous with difficulty, whereas challenge implies the potential for beneficial change (Schneider, 2001). Therefore without creating unrealistic expectations about learned optimism resolving all of the difficult issues that the team and student groups are faced with, the use of terminology that is decidedly more optimistic allows a realistic approach to the amount of control and how correct diagnostics can be used to achieve goals (Covington, 2000). Rather than create unrealistic views of what can be achieved, the use of learned optimism can instead and the focus being on challenge terminology rather than problem based terms can mean that there is a heightened desire to make realistic assessments of the factors involved with problem solving, and increases realism rather than encouraging unrealistic outcomes from challenge or goal oriented activities (Oettingen, 1996).

Beyond the application of learned optimism in relation to present challenges in the higher education environment, an added benefit of implementing these practices in our staff and student environment is the positive impact that optimism has on career, mental and educational adjustments (Bressler, Bressler \& Bressler, 2010). It is understood that by continuing to pursue change in the way in which Campus Engagement facilitates training and support to student groups that we can be a positive factor in the implementation of learned optimism and positive mindset practices in students. El-Anzi (2005) has identified that optimism correlates with strong levels of career and/or personal goals. With the future focused strategic framework implemented at Macquarie University that emphasises the role of staff to empower students to be prepared for careers and skills that will encompass not only education based readiness but also practical life related skills, the implementation of learned optimism aligns with the experience we wish the students of Macquarie University to receive.

Through realistic practices that identify opportunities for impactful change in tasks that whilst small, enhance the student experience, learned optimism has been successfully implemented within Student Engagement as an effective tool for goalbased challenges and problem solving.

Future implementation of learned optimism will involve student executives in training workshops that allow them to use tools such as 'three good things' and savouring positive experiences within their student groups so that the skills associated with learned optimism can be provided to a wider audience within the University.

\section{References}

Baumeister, R. (1988). The optimal margin of illusion. Journal of Social and Clinical Psychology, 8. 176-189.

Buchanan, G., \& Seligman, M. (1995). Explanatory Style. Erlbaum.

Bressler, L., Bressler, M. E., \& Bressler, M. S. (2010). The role and relationship of hope, optimism and goal setting in achieving academic success; a study of students enrolled in online accounting courses. Academy of Educational Leadership Journal 14(4).

Carver, C. S., \& Scheier, M. F. (1990). Origins and functions of positive and negative affect: A control-process view. Psychological Review, 97, 19 -35.

Colvin, C., \& Block, J. (1994). Do positive illusions foster mental health? An examination of the Taylor and Brown formulation. Psychological Bulletin 116. 3-20. https://doi.org/10.1037/0033-2909.116.1.3

Covington, M. (2000). Goal theory, motivation and school achievement: an integrative review. Annual Review of Psychology, 51. 171-200. https://doi.org/10.1146/annurev.psych.51.1.171

Duckworth, A., Steen, T., \& Seligman, M. (2005). Positive psychology in clinical practice. Annual Review of Clinical Psychology, 1, 629-651. https://doi.org/10.1146/annurev.clinpsy.1.102803.144154

El-Anzi, F. O. (2005). Academic achievement and its relationship with anxiety, self esteem, optimism, and pessimism in Kuwaiti students. Social Behavior and Personality, 33, 95-104. https://doi.org/10.2224/sbp.2005.33.1.95

El Sayed, S., \& Humble, S. (2018). Learned optimism: An alternative approach to the half empty glass. Bulletin (Law Society of South Australia). 40(7). 33-35.

Gregersen, T., MacIntyre, P., Finegan, K., Talbot, K., \& Claman, S. (2014). Examining emotional intelligence within the context of positive psychology interventions. Studies in Second Language Learning and Teaching, 4(2). $327-353$. https://doi.org/10.14746/ssllt.2014.4.2.8

Halama, P., \& Dedova, M. (2007). Meaning in life and hope as predictors of positive mental health: Do they explain residual variance not predicted by personality traits? Studia Psychologica, 49, 191-200.

Howard, S., \& Johnson, B. (2000). What makes the difference? Children and teachers talk about resilient outcomes for children "at risk." Educational Studies, 26, 321-337. https://doi.org/10.1080/03055690050137132 
Hoy, W., Tarter, C., \& Hoy, A. (2006). Academic optimism of schools: A force for student achievement. American Education Research Journal, 43(3). 425-446. https://doi.org/10.3102\%2F00028312043003425

Jimerson, S., Egeland, B., \& Teo, A. (1999). A longitudinal study of achievement trajectories: Factors associated with change. Journal of Educational Psychology, 91, 116-126.

Masten, A. (2001). Ordinary magic: Resilience processes in development. American Psychologist, 56, $227-238$. https://doi.org/10.1037//0003-066x.56.3.227

Metalsky, G. I., Abramson, L. Y., Seligman, M. E. P., Semmel, A., \& Peterson, C. (1982). Attributional styles and life events in the classroom: Vulnerability and invulnerability to depressive mood reactions. Journal of Personality and Social

Psychology, 43, 612-617. https://doi.org/10.1037//0022-3514.43.3.612

MacIntyre, P. D., \& Gregersen, T. (2013). Emotions that facilitate language learning: The positive broadening power of the imagination. Studies in Second Language Learning and Teaching, 2, 193-213. https://doi.org/10.14746/ssllt.2012.2.2.4

Oettingen, G. (1996). Positive fantasy and motivation. In P.M Gollwitzer and J.A Bargh (Eds.). The Psychology of Action: linking cognition and motivation to behaviour (pp. 236-259). Guildford.

Olson, K., \& Dweck, C.S. (2008). A blueprint for social cognitive development. Perspectives on Psychological Science, 3 , 193-202. https://doi.org/10.1111/j.1745-6924.2008.00074.X

Peterson, C. (2000). The future of optimism. American Psychologist, 55(1). 44-55. https://doi.org/10.1037//0003066x.55.1.44

Peterson, C. (2006). A primer in positive psychology. Oxford University Press.

Peterson, C., \& Barrett, L. C. (1987). Explanatory style and academic performance among university freshmen. Journal of Personality and Social Psychology, 53, 603-607.

Peterson, C., \& Seligman, M.E.P. (1984). Causal attribution as risk factor for depression: Theory and research. Psychological Review, 91, 347-374.

Peterson, C., Seligman, M. E. P., \& Vaillant, G. E. (1988). Pessimistic explanatory style is a risk factor for physical illness: A 35-year longitudinal study. Journal of Personality and Social Psychology, 55, 23-27. https://doi.org/10.1037//0022$\underline{3514.55 .1 .23}$

Rutter, M. (2007). Resilience, competence and coping. Child Abuse and Neglect, 31, 205-209

Seligman, M (1991). Learned Optimism. Random House Press.

Seligman, M. (1998). President's column. Positive social science. APA Monitor, 29(4). 2-5.

Seligman, M. (2004). Can Happiness Be Taught? Daedalus, 133(2), 80-87. https://doi.org/10.1162/001152604323049424

Seligman, M. (2006). Learned optimism: how to change your mind and your life. Simon \& Schuster.

Seligman, M., Steen, T., Park, N \& Peterson, C. (2005). Positive psychology progress: Empirical validation of interventions. American Psychologist, 60(5). 5-14. https://doi.org/10.1037/0003-066X.60.5.410

Schulman, P. (1999). Applying learned optimism to increase sales productivity. Journal of Personal Selling and Sales Management. 19(1). 31-37. https://doi.org/10.1080/08853134.1999.10754157

Schneider, S. (2004). In search of realistic optimism: Meaning, knowledge, and warm fuzziness. American Psychologist, 56(3). 250-263. https://doi.org/10.1037//0003-066x.56.3.250

Tariq, I., \& Zubair, A. (2015). Character strengths, learned optimism, and social competence among university students. Pakistan Journal of Psychology, 46(2), 35-51.

Ungar, M. (2008). Resilience across cultures. British Journal of Social Work, 38, 218-235. https://doi.org/10.1093/bjsw/bcl343

Wang, M.C., Haertal, G.D., \& Walberg, H.J. (1994). Educational resilience in inner cities. In M.C. Wang \& E.W. Gordon (Eds.), Educational resilience in inner-city America: Challenges and prospects (pp. 45-72). Hillsdale, NJ: Erlbaum.

Zito, J.R., Adkins, M., Gavins, M., Harris, K., \& Graham, S. (2007). Self-regulated strategy development: Relationship to the social-cognitive perspective and the development of self-regulation. Reading and Writing Quarterly, 23, 77-95. https://doi.org/10.1080/10573560600837693

\section{Please cite this article as:}

Chadwick, M. (2019). A reflection on harnessing learned optimism, resilience and team growth behaviour in order to support student groups. Student Success, 10(3), 104-111. https://doi.org/10.5204/ssj.v10i3.1410

This Emerging Initiative has been accepted for publication in Student Success. Please see the Editorial Policies under the 'About' section of the Journal website for further information.

(c) (1) This work is licensed under a Creative Commons Attribution 4.0 International Licence. As an open access journal, articles are free to use with proper attribution. ISSN: 2205-0795 